Journal of Animal and Veterinary Advances 11 (14): 2469-2479, 2012

ISSN: $1680-5593$

(C) Medwell Journals, 2012

\title{
The Activation of Akt/protein Kinase B Signaling Affects the Expression of Histone H3 Lysine 27 Methylase and Demethylase Genes in Mouse Cell Lines
}

\author{
${ }^{1,2}$ Yunsheng Zhang, ${ }^{2,3} \mathrm{Jing} \mathrm{Li},{ }^{1}$ Xiaoxiang Hu and ${ }^{1}$ Ning Li \\ ${ }^{1}$ The State Key Laboratory for AgroBiotechnology, \\ China Agricultural University, 100193 Beijing, China \\ ${ }^{2}$ Xinjiang Agricultural Reclamation Academy, \\ The Research Institute of Animal Husbandry and Veterinary, 832000 Shihezi, China \\ ${ }^{3}$ Institute of Animal Science, Shihezi University, 832000 Xinjiang, China
}

\begin{abstract}
H3K27 methylation plays an important role in the regulation of gene expression and chromatin stability and its expression is dynamically regulated by both specific methylases and demethylases. During development, the regulation of these enzymes is fine-tuned to co-determine the appropriate level of H3K27 methylation thus ensuring correct gene expression. However, it is not completely clear how this regulation is realized. Here, we found that Akt (Aktl and Akt2), H3K27 methylases (Ezhl and Ezh2) and demethylases (Jmjd3 and Utx) displayed varying levels of RNA and protein expression in mouse cell lines. Ezh2 was upregulated $(\mathrm{p}<0.05)$ at the protein level in an IGF-1 -treated $\mathrm{C} 2 \mathrm{C} 12$ cell line. The overexpression of $\mathrm{p}$-Akt through myr-Akt vector transfection greatly downregulated the mRNA levels of Ezh1, Jmjd3 and Utx $(\mathrm{p}<0.01)$ but not Ezh2 $(\mathrm{p}>0.05)$. Therefore, the data suggest that the expression of both $\mathrm{H} 3 \mathrm{~K} 27$ methylase and demethylase genes is involved in the activation of the IGF-1/PI3K/Akt pathway.
\end{abstract}

Key words: Epigenetics, H3K27 methylation, Akt, Ezh1, Ezh2, Jmjd3, Utx

\section{INTRODUCTION}

Histone post-translational modifications are widely involved in cell reprogramming (Sasaki and Matsui, 2008), lineage specification (Mohn and Schubeler, 2009; Surani et al., 2007) and carcinogenesis (Esteller, 2008; Feinberg et al., 2006). Previous studies have revealed that these modifications have significant functions in the stabilization of chromatin structure maintaining specific gene expression that preserves the distinctive features of different cell types in multicellular organisms. H3K27 trimethylation occurs in the promoter region of static genes and silenced chromatin domains (Barski et al., 2007; Kouzarides, 2007; Peters et al., 2003) and is thus regarded as an important repressive gene expression regulator.

H3K 27 can be mono, di or trimethylated by specific methyltransferases (Peters et al., 2003; Steward et al., 2006) with the type of modification depending on the stage of development or differentiation. Ezh2 containing a SET domain has been shown to be involved in H3K27 methyltransferase activity (Czermin et al., 2002; Kuzmichev et al., 2002) and it is highly expressed in prostate cancer (Varambally et al., 2002), breast cancer
(Kleer et al., 2003) and lymphoma (Van Kemenade et al., 2001). Ezh1, a homolog of Ezh2 is more highly transcribed in kidney, brain and skeletal muscle tissues (Laible et al., 1997), it can also catalyze H3K 27 methylation. Both Ezh1 and Ezh2 can methylate H3K27 during epidermal differentiation in vitro (Ezhkova et al., 2011). Therefore, Ezh1 and Ezh2 are essential for the generation of H3K27 methylation and the correct regulation of gene expression. The H3K 27 methylation level was dynamically altered by the addition or removal of methyl groups in response to certain stimuli (Bannister et al., 2002) which was confirmed by the discovery of histone demethylases including LSD (Shi et al., 2004) and the catalytically active Jmjc domain family (Tsukada et al., 2006). Demethylases can specifically remove methyl groups at the particular sites and thus antagonize the effects of methylases. The H3K27 demethylases Utx and Jmjd3 are recruited to the promoters of individual genes to relieve their repression (Seenundun et al., 2010; Sen et al., 2008). Jmjd3 expression is upregulated or activated when stimulated by cell cytokines and the RAS-RAF pathway, allowing repressed genes to be transcribed (Agger et al., 2009; De Santa et al., 2007). During development and

Corresponding Author: Ning Li, The State Key Laboratory for AgroBiotechnology, China Agricultural University, 100193 Beijing, China 
differentiation, Utx and Jmjd3 are activated to decrease $\mathrm{H} 3 \mathrm{~K} 27$ methylation level after the appropriate signals are received.

Akt/PKB (Protein Kinase B), a major downstream target gene of the IGF-1/PI3K/Akt pathway plays an important role in cell growth (Potter et al., 2002), differentiation (Lopez-Carballo et al., 2002) and survival (Datta et al., 1997). Cha et al. (2005) reported an inverse correlation between p-Akt and $\mathrm{H} 3 \mathrm{~K} 27$ trimethylation in human cell lines and determined that Akt phosphorylated Ezh2 at serine 21, impairing its methyltransferase activity. A recent study found that Eed, Ezh2 and Suz12 were markedly downregulated in a murine skin repair model whereas Jmjd3 and Utx were significantly upregulated, accompanied by markedly decreased H3K27 trimethylation (Shaw and Martin, 2009). This finding implies that the expression of $\mathrm{H} 3 \mathrm{~K} 27$ methylases and demethylases may be synchronously regulated to determine the $\mathrm{H} 3 \mathrm{~K} 27$ methylation level in response to various stimuli. However, the mechanism by which this process is regulated remains unknown.

In this study, to determine whether Akt signaling affects the expression of $\mathrm{H} 3 \mathrm{~K} 27$ methylases and demethylases, researchers examined the expression of these genes at the RNA and protein levels in mouse cell lines and monitored changes in their levels when the IGF-1/PI3K/Akt pathway was activated by IGF-1 or myrAkt vector transfection. Researchers found that Ezhl, Ezh2, Jmjd3 and Utx displayed varying expression levels in the $\mathrm{C} 127, \mathrm{C} 2 \mathrm{C} 12,3 \mathrm{~T} 3-\mathrm{L} 1$ and NIH/3T3 cell lines. H3K27 methylase and demethylase gene expression are thus involved in the activation of the IGF-1/PI3K/Akt pathway.

\section{MATERIALS AND METHODS}

Materials and antibodies: Antibodies against phospho-Akt (473S), pan-Akt, Akt1, Akt2 and H3 were purchased from Cell Signaling Technology (Beverly, MA, USA). Antibodies against Ezh2 and trimethylated H3K27 were obtained from Millipore (Bedford, MA, USA). An antibody against Ezhl was purchased from Epitomics (Burlingame, CA, USA). An antibody against Utx was obtained from Bethyl Laboratories (Montgomery, TX, USA). An antibody against Jmjd3 was purchased from Abgent (San Diego, California, USA). Human recombinant IGF-1 was obtained from Sigma (St. Louis, MO, USA). FBS and CS were purchased from Hyclone (Thermo, Boston, MA, USA). NCS was purchased from Gibco (Invitrogen, Carlsbad, CA, USA). Cell culture medium (DMEM) was obtained from Invitrogen (Carlsbad, CA, USA). C127 (mouse mammary gland epithelial) and 3T3-L1 (mouse embryonic preadipocyte) cell lines were purchased from
ATCC. NIH/3T3 (mouse embryonic fibroblast) and C2C12 (mouse muscle myoblast) cell lines were from the BeijingUnion MedicalCell Bank.

Cell culture and transfection: Cell lines were maintained in DMEM medium supplemented with $10 \%$ heatinactivated serum (C127 and $\mathrm{C} 2 \mathrm{C} 12$ supplemented with FBS; 3T3-L1 supplemented with NCS; NIH/3T3 supplemented with $\mathrm{CS}$ ), $100 \mathrm{U} \mathrm{mL}^{-1}$ penicillin and $100 \mu \mathrm{g} \mathrm{mL}^{-1}$ streptomycin. All cell lines were incubated at $37^{\circ} \mathrm{C}$ in humidified $95 \%$ air containing $5 \% \mathrm{CO}_{2}$. NIH/3T3 cells were transfected with $4 \mu \mathrm{g}$ DNA per $1 \times 10^{6}$ cells using the Amaxa Cell Line Nucleofector kit (Amaxa Biosystems, Gaithersburg, MD, USA) according to the manufacturer's instructions.

RNA extraction and reverse transcription: Total RNA was extracted using an RNeasy mini kit (Qiagen, Hilden, Germany) with genomic DNA removed using RNase-free DNase I (Qiagen, Hilden, Germany) according to the manufacturer's instructions. The RNA concentration was determined using a NanoDrop spectrophotometer (Thermo Scientific, Waltham, MA). Reverse transcription was performed with $1 \mu \mathrm{g}$ total RNA using the $\mathrm{M}-\mathrm{MLV}$ kit (Promega, Madison, WI, USA) following the manufacturer's protocol.

Quantitative real-time PCR: Real-time quantitative PCR was performed on a LightCycler 480 (Roche Biochemicals, Mannheim, Germany) in a total volume of $15 \mu \mathrm{L}$ with SYBR Green I Mixture (Roche Biochemicals, Mannheim, Germany). The primers used in quantitative real-time PCR for Akt1, Akt2, Ezhl (Rugg-Gunn et al., 2010), Ezh2 (Rugg-Gunn et al., 2010), Jmjd3 (De Santa et al., 2007), Utx (Xu et al., 2008) and Gapdh are shown in Table 1. The following PCR conditions were used: $95^{\circ} \mathrm{C}$ for $5 \mathrm{~min}$ followed by 40 cycles of $95^{\circ} \mathrm{C}$ for $15 \mathrm{sec}$ and $60^{\circ} \mathrm{C}$ for $1 \mathrm{~min}$ and a final melting curve was performed from $65-95^{\circ} \mathrm{C}$. The amplification products were recovered, sequenced and compared against GenBank sequences using the BLAST tool (NCBI). Each of the amplified DNA products was identical to the sequence of its target gene. All quantitative real-time PCR samples were run in triplicate. The $2^{-\Delta \Delta \mathrm{Ct}}$ Method was used to analyze the results (Livak and Schmittgen, 2001).

Plasmid construction: The Akt1 and Akt2 CDS nucleotide sequences were amplified using primers P2 and P4 (Table 1), respectively containing BamHI and NotI restriction sites, an N-terminal myristoylation tag nucleotide sequence (Boutin, 1997; Mitsuuchi et al., 1998) and a C-terminal c-myc tag nucleotide sequence 
Table 1: Sequences of the primers used for PCR and quantitative RT-PCR

\begin{tabular}{|c|c|c|c|c|}
\hline Primer name & Gene symbol & References & Primer sequence $5^{\prime}-3^{\prime}$ & Product size (bp) \\
\hline \multirow[t]{2}{*}{ P1 } & Akt1 & NM_009652 & F:CGCCAAGGATGAGGTTGC & 104 \\
\hline & & & R:GGTCGTGGGTCTGGAATGAG & \\
\hline \multirow[t]{4}{*}{$\mathrm{P} 2$} & & & F: CGCGGATCCGCCACCATGGGGAGCAGCAAGAG & 1,527 \\
\hline & & & CAAGCCCAAGATGAACGACGTAGCCATTGTG & \\
\hline & & & R: ATTTGCGGCCGCTCACAGATCCTCTTCTGAGAT & \\
\hline & & & GAGTTTTTGTTCGGCTGTGCCACTGGCTGAG & \\
\hline \multirow[t]{2}{*}{ P3 } & Akt2 & NM_001110208 & $\overline{\text { F:CCACGACCCAACACCTTTGT }}$ & 102 \\
\hline & & & R:CCGCATCCACTCTTCCCTC & \\
\hline \multirow[t]{4}{*}{ P4 } & & & F: CGCGGATCCGCCACCATGGGGAGCAGCAAGAGC & 1,530 \\
\hline & & & AAGCCCAAGATGAATGAGGTATCTGTCATCAAAG & \\
\hline & & & R:ATTTGCGGCCGCTCACAGATCCTCTTCTGAGATG & \\
\hline & & & AGTTTTTGTTCCTCTCGGATGCTGGCTGAGT & \\
\hline \multirow[t]{2}{*}{ P5 } & Ezh1 & NM_007970 & F:CGAGTCTTCCACGGCACCTA & 89 \\
\hline & & & R:GCAAACTGAAAGACCTGCTTGC & \\
\hline \multirow[t]{2}{*}{ P6 } & Ezh2 & NM_007971 & F:CCTTCCATGCAACACCCAAC & 100 \\
\hline & & & R:GCTCCCTCCAGATGCTGGTAA & \\
\hline \multirow[t]{2}{*}{ P7 } & Jmjd3 & NM_001017426 & F:CCCCCATTTCAGCTGACTAA & 199 \\
\hline & & & R:CTGGACCAAGGGGTGTGTT & \\
\hline \multirow[t]{2}{*}{ P8 } & Utx & NM_009483 & F:AAGGCTGTTCGCTGCTACG & 260 \\
\hline & & & R:GGATCGACATAAAGCACCTCC & \\
\hline \multirow[t]{2}{*}{ P9 } & Gapdh & NM_008084 & F:AGGTCGGTGTGAACGGATTTG & 123 \\
\hline & & & R:TGTAGACCATGTAGTTGAGGTCA & \\
\hline
\end{tabular}

(Sato et al., 2006). The PCR conditions were as follows: $95^{\circ} \mathrm{C}$ for $5 \mathrm{~min}$ followed by 35 cycles of $95^{\circ} \mathrm{C}$ for $30 \mathrm{sec}$, $60^{\circ} \mathrm{C}$ for $30 \mathrm{sec}$ and $72^{\circ} \mathrm{C}$ for $2 \mathrm{~min}$. The amplified products were recovered and digested with BamHI and NotI restriction enzymes (New England Biolabs, Beverly, MA, USA) and then inserted into pcDNA3.1(+) (Invitrogen, Carlsbad, CA, USA) that had been predigested with BamHI and NotI. Positive clones were sequenced and BLASTed against the GenBank sequence database (NCBI) and the results showed that each of the amplified DNA fragments was correct. The resulting vectors were named myr-Aktl and myr-Akt2, respectively.

Protein extraction and Western blotting: After reaching $70-80 \%$ confluence or $48 \mathrm{~h}$ after transfection, the cells were washed with cold DPBS and then protein was extracted in immunoprecipitation buffer (Beyotime Biotech, Nantong, China) containing protease inhibitor cocktail (Roche Biochemicals, Mannheim, Germany) and phosphatase inhibitor (Roche Biochemicals, Mannheim, Germany) after 30 min of incubation on ice. The lysate was separated by centrifugation and the supernatant was collected. Histones were extracted as previously described by Shechter et al. (2007). The protein concentration was determined using a BAC kit (Beyotime Biotech, Nantong, China). Protein was denatured in SDS sample buffer, boiled for $5 \mathrm{~min}$ and then subjected to SDSPAGE with equal amounts in each lane. After electrophoresis, the protein on the gel was transferred to a PVDF membrane (Millipore, Bedford, MA, USA) and blocked in 5\% milk TBST buffer for $1 \mathrm{~h}$. The membrane was then probed with monoclonal or polyclonal primary antibodies against the proteins of interest using the antibody concentrations recommended by the manufacturers. Subsequently, a Horseradish Peroxidase (HRP) conjugated secondary antibody (Jackson ImmunoResearch, West Grove, PA, USA) was used to detect the primary antibodies. After incubation with the primary and secondary antibodies, the membranes were washed three times with TBST for $10 \mathrm{~min}$ each. The antigen-antibody complex was detected using an ECL kit (Thermo, Boston, MA, USA) according to the manufacturer's instructions.

Statistical analyses: Western blot bands were quantified using the Gel-Pro imaging software (Media Cybernetics, Silver Spring, MD, USA). The values shown represent the average of at least three independent experiments and the data were expressed as the mean $\pm \mathrm{SD}$ and analyzed with one-way ANOVA. The $\mathrm{p}<0.05$ was considered statistically significant. Error bars indicate standard deviations. The different lowercase letters indicate statistically significant $(p<0.05)$ and extremely significant $(p<0.01)$ values.

\section{RESULTS AND DISCUSSION}

The levels of p-Akt and H3K27 trimethylation in mouse cell lines: Cha et al. (2005) reported that p-Akt levels were inversely correlated with $\mathrm{H} 3 \mathrm{~K} 27 \mathrm{me} 3$ levels in human cell lines, researchers speculated that a similar phenomenon would be observed in mouse cell lines. Researchers used Western blotting to investigate the relationship between p-Akt levels and $\mathrm{H} 3 \mathrm{~K} 27 \mathrm{me} 3$ levels in the $\mathrm{C} 127, \mathrm{C} 2 \mathrm{C} 12,3 \mathrm{~T} 3-\mathrm{L} 1$ and NIH/3T3 cell lines. 

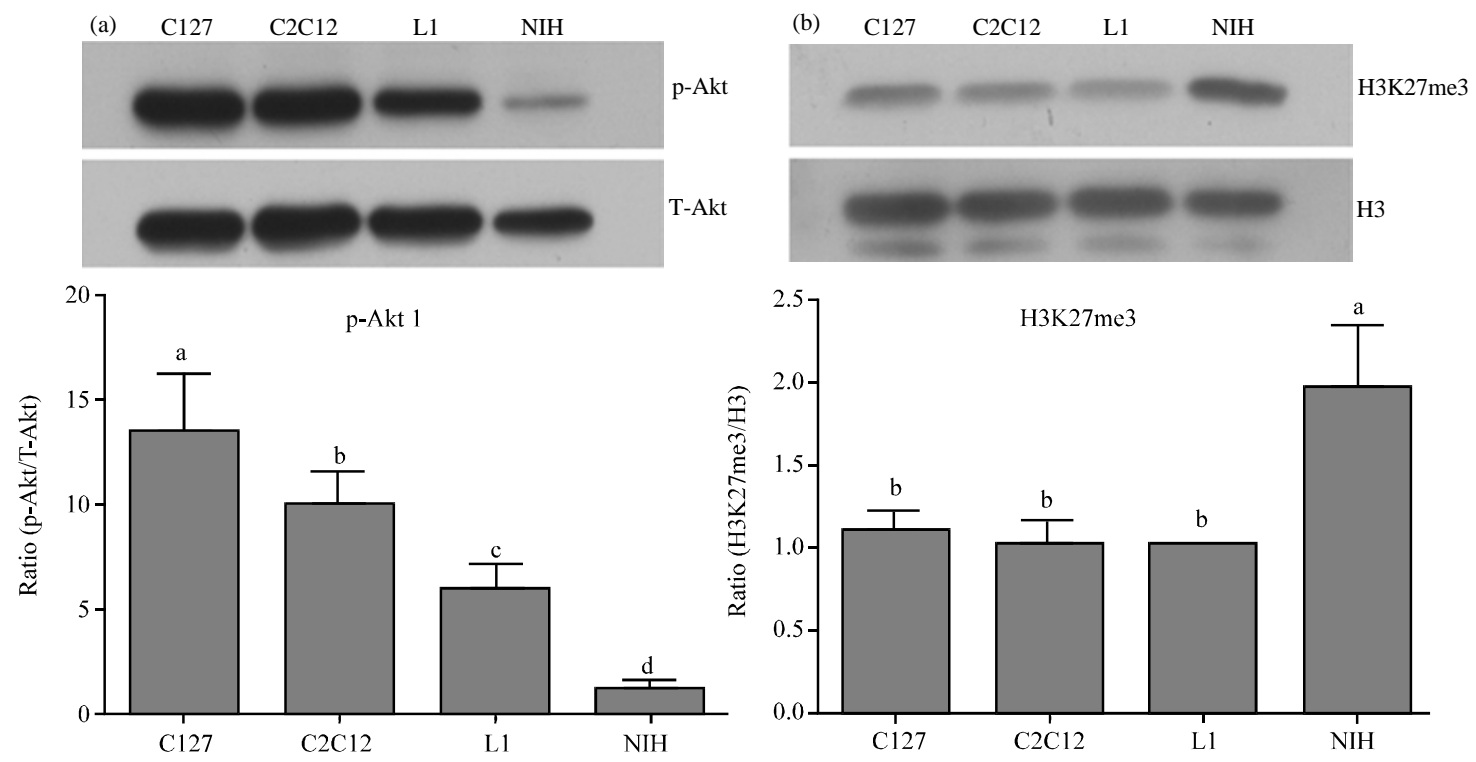

Fig. 1: Detection of p-Akt and H3K27 trimethylation in mouse cell lines. Western blot analysis of; a) p-Akt and b) H3K27 trimethylation in the $\mathrm{C} 127, \mathrm{C} 2 \mathrm{Cl} 2,3 \mathrm{~T} 3-\mathrm{L} 1$ and $\mathrm{NIH} / 3 \mathrm{~T} 3$ cell lines. The black bars represent ratios of the densities of the corresponding Western blot bands normalized to the internal reference gene. L1, 3T3-L1 cell line; NIH, $\mathrm{NIH} / 3 \mathrm{~T} 3$ cell line

Researchers found that the p-Akt contents were significantly different $(\mathrm{p}<0.05)$ among these cell lines with C127 showing the highest $\mathrm{p}-$ Akt level $(\mathrm{p}<0.05$; Fig. 1a). The lowest p-Akt level was found in NIH/3T3 $(\mathrm{p}<0.05)$. The NIH/3T3 cell line showed the highest H3K27 trimethylation level $(\mathrm{p}<0.01)$ but there were no significant differences ( $p>0.05)$ among the remaining cell lines (Fig. 1b).

Different RNA and protein levels of Akt1, Akt2, H3K27 methylases (Ezh1 and Ezh2) and demethylases (Jmjd3 and Utx): Because p-Akt levels are affected by Aktl and Akt2 expression, researchers expected that the level of H3K27 trimethylation would be regulated by methylases (Ezh1 and Ezh2) or demethylases (Jmjd3 and Utx). Thus, researchers were interested in determining how these genes contribute to increased p-Akt expression corresponding to reduced $\mathrm{H} 3 \mathrm{~K} 27 \mathrm{me} 3$ levels. First, researchers examined Aktl and Akt2 mRNA and protein expression. The $\mathrm{C} 127$ and $\mathrm{C} 2 \mathrm{C} 12$ cell lines both displayed higher levels of Akt1 and Akt2 mRNAs than did the 3T3-L1 and NIH/3T3 $(\mathrm{p}<0.05)$ lines (Fig. 2a).

The $\mathrm{C} 127$ and $\mathrm{C} 2 \mathrm{C} 12$ lines displayed elevated Akt2 protein expression (Fig. 2b) compared with the 3T3-L1 and $\mathrm{NIH} / 3 \mathrm{~T} 3$ lines $(\mathrm{p}<0.05)$. Second, researchers investigated the mRNA and protein levels of Ezh1, Ezh2, Jmjd3 and Utx in these cell lines. The expression of Jmjd3 mRNA (Fig. 3a) was the highest in $\mathrm{C} 2 \mathrm{C} 12(\mathrm{p}<0.05)$. The 3T3-L1 cell line had the lowest Ezh2 mRNA expression of all cell lines tested $(\mathrm{p}<0.01)$. The protein expression levels of Ezh1, Ezh2, Jmjd3 and Utx (Fig. 3b) were highest in C127 (p<0.05).

H3K27 methylase and demethylase gene expression upon activation of the IGF-1/PI3K/Akt pathway: Ezh1, Ezh2, $\mathrm{Jmjd} 3$ and Utx were variably expressed in these mouse cell lines. Researchers were thus interested in determining whether the H3K27 methylases and demethylases are involved in the IGF-1/PI3K/Akt pathway. Researchers detected increases in p-Akt levels beginning at $10 \mathrm{~min}$ after IGF-1 treatment and peaking at $3 \mathrm{~h}$. The Ezh2 levels increased from 6-24 h while the levels of Ezh1 and Jmjd3 remained unchanged ( $p>0.05)$; the levels of Utx changed but not significantly ( $p>0.05$; Fig. 4). Similar results were also observed in the NIH/3T 3 cell line. To confirm that an increase in p-Akt promotes Ezh2 expression, researchers constructed the myr-Aktl and myr-Akt2 vectors to induce high p-Akt levels. The transfection efficiency in the $\mathrm{NIH} / 3 \mathrm{~T} 3$ cell line was $80 \%$. The cells were harvested at 24 and $48 \mathrm{~h}$ after transfection to investigate the mRNA and protein expression of Ezh1, Ezh2, Jmjd3 and Utx. The results showed that increased p-Akt levels greatly decreased the mRNA expression of Ezhl, Jmjd3 and Utx $(\mathrm{p}<0.01)$ but not that of Ezh2 ( $>00.05$; Fig. 5a). Transfection with the myr-Aktl vector yielded the highest expression of p-Akt compared with the control followed by myr-Akt2 (Fig. 5b). The Ezh1 and Utx levels slightly decreased with protein expression $(p<0.05)$, Ezh2 and Jmjd3 levels remained the same ( $p>0.05)$. 

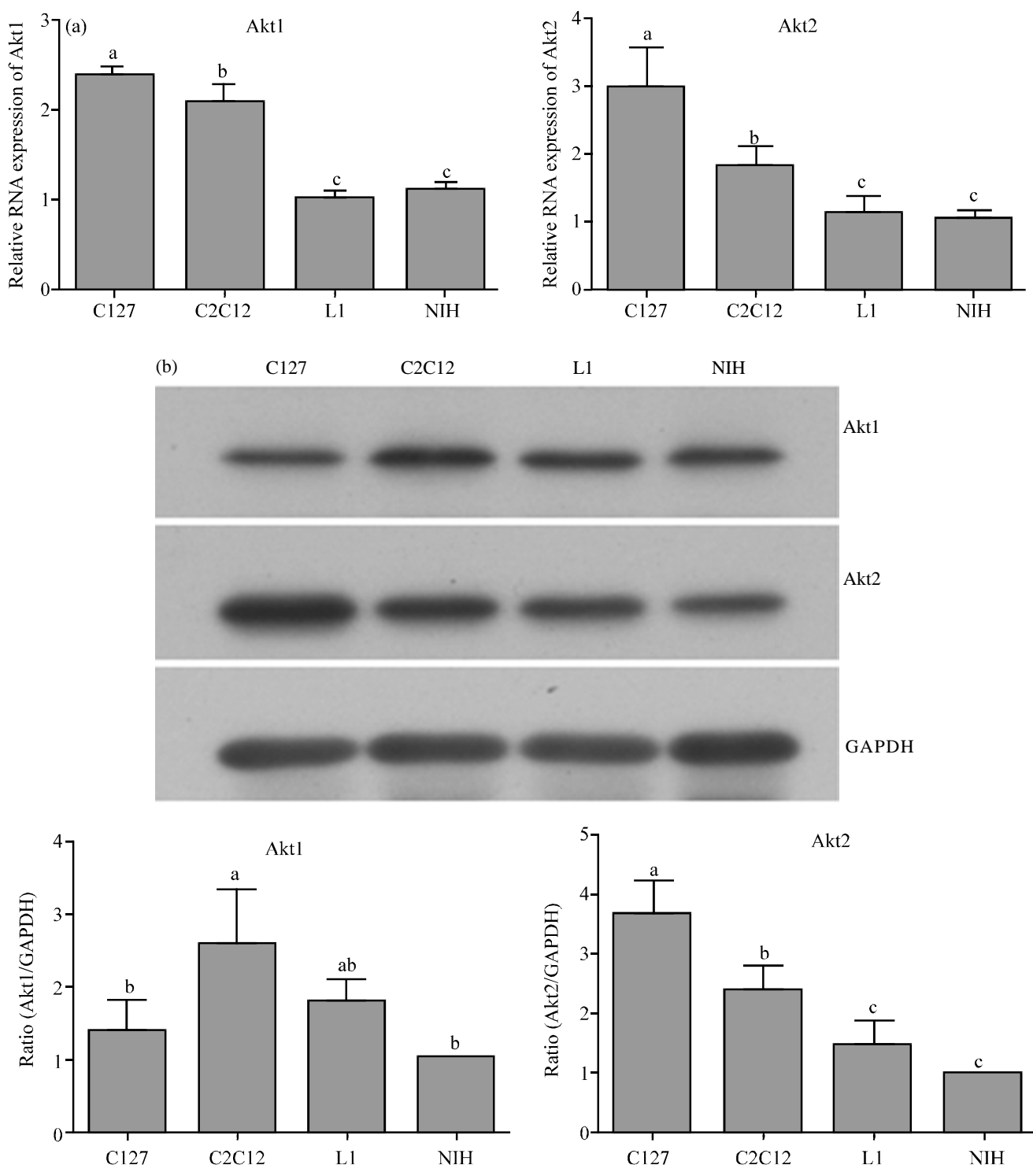

Fig. 2: a) Levels of Aktl and Akt2 mRNA and protein in mouse cell lines. Total RNA was isolated from C127, C2C12, 3T3L1 and NIH/3T3 cell lines and real-time quantitative PCR was used to determine Akt1 and Akt2 levels; b) The mRNA expression levels were normalized to GAPDH mRNA expression. Western blotting to ascertain Akt1 and Akt2 expression in the $\mathrm{C} 127, \mathrm{C} 2 \mathrm{C} 12,3 \mathrm{~T} 3-\mathrm{L} 1$ and NIH/3T3 cell lines

H3K27 trimethylation is regarded as a repressive histone modification and is always associated with silenced gene promoters (Barski et al., 2007). Many of the targeted genes are transcription factors (Bernstein et al., 2006; Lee et al., 2006) and it is clear that histone methylation plays a crucial role in gene expression during development. H3K27 methylation is dynamically regulated by methylases and demethylases. Researchers performed real-time PCR and Western blot to determine the expression levels of H3K27 methylase and demethylase genes and found that Ezh1, Ezh2, Jmjd3 and Utx were variably expressed in mouse cell lines with Ezh2 and Utx showing greater susceptibility in the activation of the IGF-1/PI3K/Akt pathway than Jmjd3 and Ezhl with respect to RNA and protein expression levels.

H3K 27 trimethylation appears to fine-tune the regulation of gene expression, both spatially and temporally. Barski et al. (2007) reported elevated H3K27 trimethylation on the promoters of repressed genes and its absence on active genes. The uneven distribution of $\mathrm{H} 3 \mathrm{~K} 27$ trimethylation throughout the whole genome is dynamically regulated by methylases (Ezh1 and Ezh2) and 

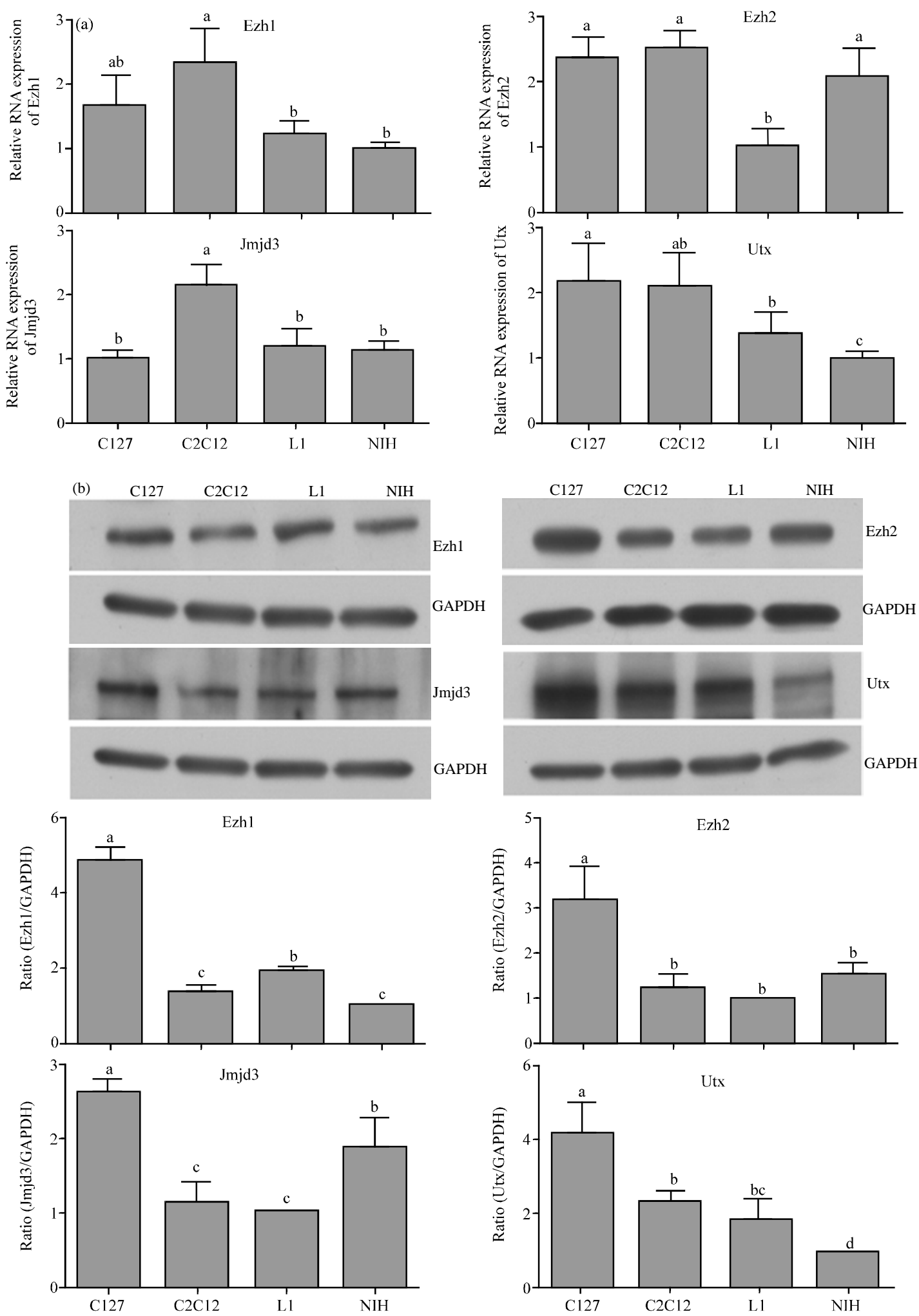

Fig. 3: a) The expression of Ezhl, Ezh2, Jmjd3 and Utx mRNA and protein in mouse cell lines. Real-time quantitative PCR was used to determine Ezh1, Ezh2, Jmjd3 and Utx mRNA expression levels; b) Western blotting was used to detect Ezh1, Ezh2, Jmjd3 and Utx protein expression levels; in the C127, C2C12, 3T3-L1 and NIH/3T3 cell lines 

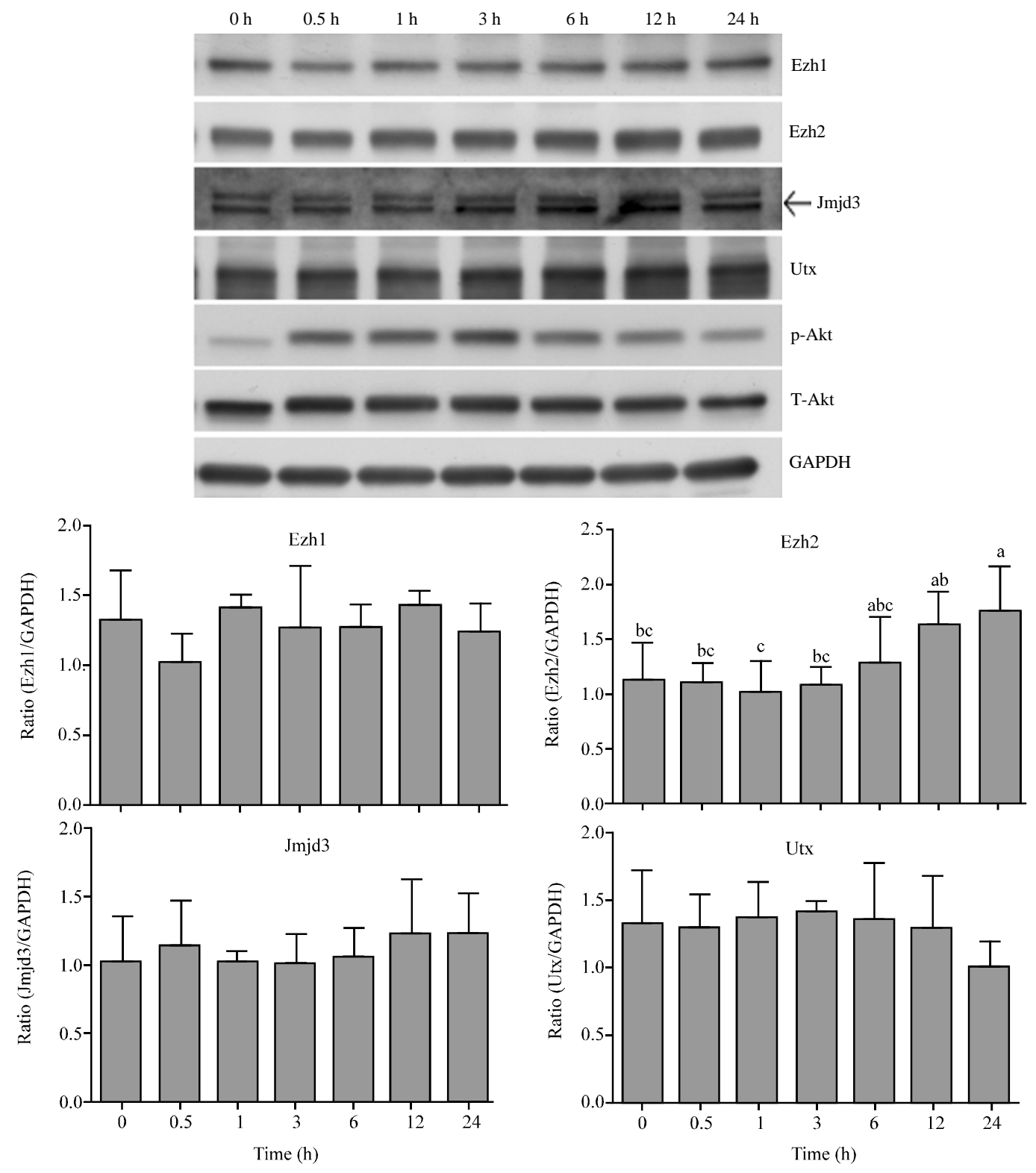

Fig. 4: The protein levels of Ezh1, Ezh2, Jmjd3 and Utx following IGF-1 administration. C2C12 was treated with $50 \mathrm{ng} \mathrm{mL}{ }^{-1} \mathrm{IGF}-1$ from 0-24 h. Protein was harvested at different timepoints and analyzed for Ezhl, Ezh2, Jmjd3, Utx, p-Akt, total Akt and GAPDH expression

demethylases (Jmjd3 and Utx) during development. Mutation of Ezh2Y641 increased the levels of H3K27 trimethylation in B-cells and lymphoma tissues (Bodor et al., 2011). Ezh2 knockdown reduced the levels of H3K27me3; similarly, the phosphorylation of Ezh2 at Ser21 also weakened its catalytic activity and decreased the level of H3K27me3 (Cha et al., 2005). Utx mutations have been detected in multiple types of cancer but no correlation of global H3K27me 3 and H3K 4 me 3 levels has been reported in Utx-null lines or wild-type samples
(Van Haaften et al., 2009). When macrophages were activated by stimulation with either IL-4 or STAT6, Jmjd3 expression was upregulated and the level of $\mathrm{H} 3 \mathrm{~K} 27$ methylation consequently decreased (Ishii et al., 2009). Although, it is known that H3K27 methylation can be upregulated by methylases and downregulated by demethylases, the mechanism by which these functional antagonism enzymes interact to co-determine H3K27 methylation level has remained obscure. The results demonstrate that Ezh1, Ezh2, Jmjd3 and Utx are expressed 

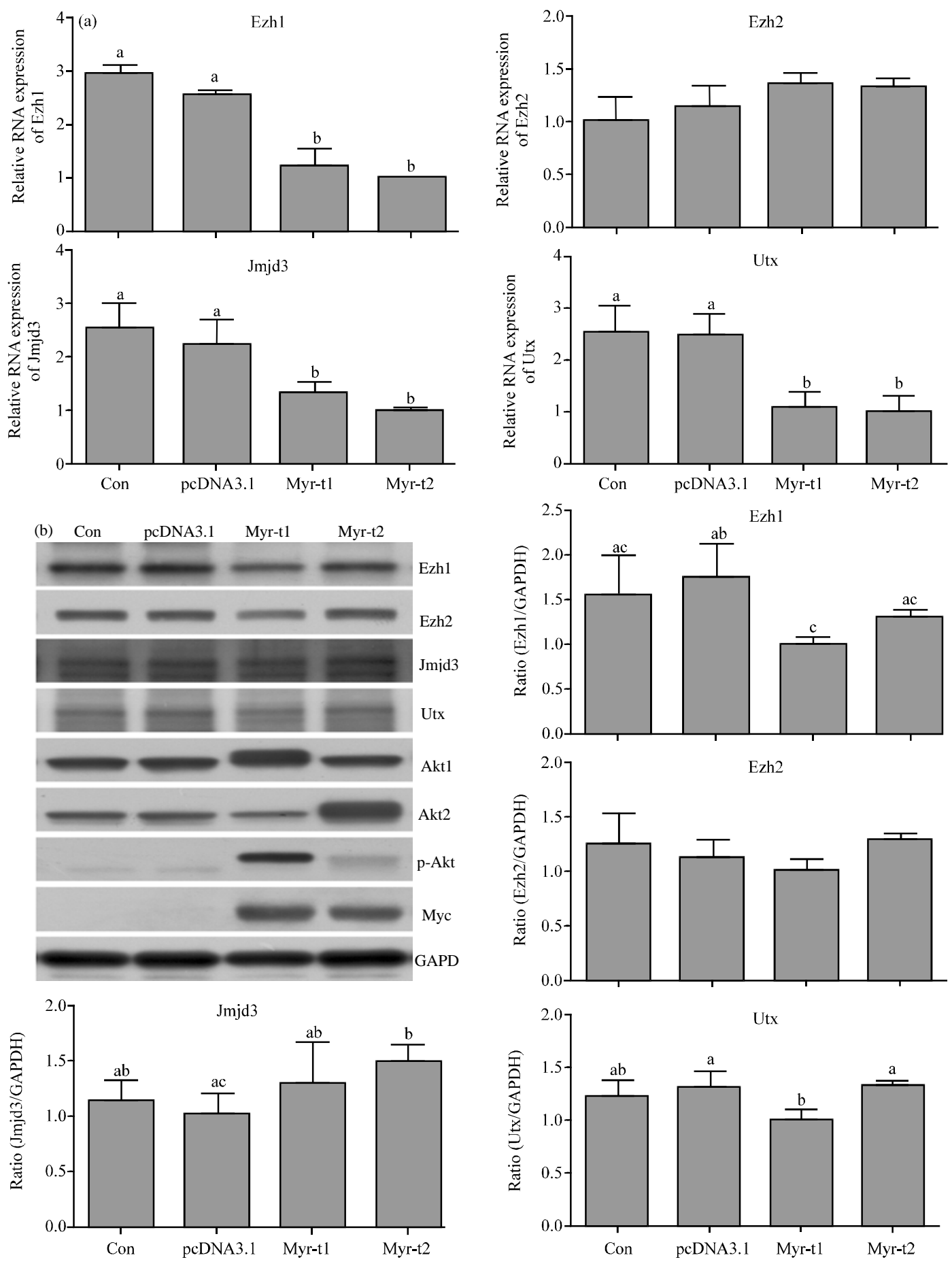

Fig. 5: The expression levels of Ezh1, Ezh2, Jmjd3 and Utx mRNA and protein in NIH/3T3 cells transfected with the myrAktl and myr-Akt2 plasmids. Total RNA was isolated at $24 \mathrm{~h}$ after myr-Aktl and myr-Akt 2 transfection; a) Realtime quantitative PCR was used to determine Ezhl, Ezh2, Jmjd3 and Utx mRNA expression levels; b) Protein was harvested $48 \mathrm{~h}$ after myr-Akt1 and myr-Akt2 transfection; Western blotting was used to evaluate Ezh1, Ezh2, Jmjd3, Utx, Akt1, Akt2, myc, p-Akt and GAPDH protein expression. The control received no treatment. Con, control, pcDNA3.1, pcDNA3.1 plasmid transfection; Myr-t1, myr-Akt1 vector transfection; Myr-t2, myr-Akt2 vector transfection 
simultaneously but are expressed differentially among these mouse cell lines, implying that $\mathrm{H} 3 \mathrm{~K} 27$ methylation may be coordinately regulated by these enzymes at the protein level.

According to a prior study, p-Akt and H3K27 trimethylation have an inverse relationship in human cell lines. In the study, researchers also found that the $\mathrm{C} 127$, C2C12 and 3T3-L1 lines expressed high levels of p-Akt accompanied with low $\mathrm{H} 3 \mathrm{~K} 27 \mathrm{me} 3$ levels; in contrast, $\mathrm{NIH} / 3 \mathrm{~T} 3$ displayed the opposite behavior. When the cell lines were treated with IGF-1, researchers found that Ezh2 was upregulated and Utx expression was slightly altered but not significantly different after $12 \mathrm{~h}$. During epidermal wound healing and the senescence of human multipotent stem cells, Ezh2 and Suz1 2 are significantly downregulated and accompanied by marked upregulation of Jmjd3 or Utx (Jung et al., 2010; Shaw and Martin, 2009). It remains unclear how methylases and demethylases expression levels are altered during these processes. The results showed that the expression of $\mathrm{H} 3 \mathrm{~K} 27$ methylases and demethylases are stimulated simultaneously in response to IGF-1. Researchers also found that myr-Akt acted to continuously increase p-Akt levels and observed that Ezh1, Ezh2 and Utx were downregulated at the mRNA level but no change was detected in Ezh2. Researchers speculate that methylases and demethylases collaboratively regulate $\mathrm{H} 3 \mathrm{~K} 27 \mathrm{me} 3$ expression in response to signal stimulation but further investigations are needed to confirm this hypothesis and the cofactors of these enzymes should be considered.

Ezh2 fine-tunes the regulation of $\mathrm{H} 3 \mathrm{~K} 27$ methylation to ensure the accuracy of gene expression during development. Several microRNAs have been found to suppress Ezh2 expression and decrease H3K27me3 levels (Varambally et al., 2008; Wong and Tellam, 2008). Ezh2 is also downregulated by small molecules (Fiskus et al., 2009). Ectopically expressed Ezh2 shortens the G1 phase to promote proliferation in primary mouse embryonic fibroblasts (Bracken et al., 2003). Researchers detected an increase in the expression of Ezh2 at $6 \mathrm{~h}$ after stimulation with IGF-1. However, Bredfeldt et al. (2010) reported that Ezh2 expression levels remained unchanged or decreased slightly within $60 \mathrm{~min}$ when E2-BSA and DES were used to induce p-Akt. Researchers speculate that this difference in behavior may be caused by other distinct down stream target genes. When the myr-Akt vector was used to increase p-Akt levels, rersearchers unexpectedly observed that both the mRNA and protein expression of Ezh2 were nearly unchanged. Because IGF-1 can activate both the PI3K/Akt and MEK/ERK pathways (Laviola et al., 2007), this finding implies that downstream target genesother than p-Akt can promote increased Ezh2 expression as confirmed by a recent report that the MEK-ERK1/2-Elk-1 pathway regulates Ezh2 overexpression and an Akt inhibitor does not affect
Ezh2 expression (Fujii et al., 2011). Researchers also observed that high levels of p-Akt did not affect Ezh2 expression. Because high Ezh2 expression leads to abnormal gene expression in various cancer cells, further studies of the mechanism of Ezh2 expression regulation may contribute to an improved understanding of its functions in cancer.

\section{CONCLUSION}

In this study, the results suggest that the IGF1/PI3K/Akt pathway affects the expression of $\mathrm{H} 3 \mathrm{~K} 27$ methylases and demethylases at the RNA and protein levels. Ezh1, Ezh2, Jmjd3 and Utx are differentially expressed in different mouse cell lines and the responses of Ezh2 and Utx are more affected by the activation of the IGF-1/PI3K/Akt pathway than are Ezhl and Jmjd3.

\section{ACKNOWLEDGEMENTS}

This research was supported by the State Major Basic Research Development Program of China under Grant No. 2009CB941600 and the National Key Scientific Program of China under Grant No. 2011ZX08009-003-006. Researchers thank Professor Yaofeng Zhao for the helpful suggestions and we also thank Wenjie Liu, Tongxin Liu and Yang Lv for their technical assistance.

\section{NOMENCLATURE}

$\begin{array}{ll}\text { IGF-1 } & =\text { Insulin-like Growth Factor 1 } \\ \text { PI3K } & =\text { Phosphatidylinositol 3-Kinase } \\ \text { Akt/PKB } & =\text { Protein Kinase B } \\ \text { p-Akt } & =\text { Phosphorylated Akt (Ser473) } \\ \text { T-Akt } & =\text { Total Akt protein } \\ \text { H3K4/27me3 } & =\text { Histone H3 trimethylated at lysine 4/27 } \\ \text { EZH1/2 } & =\text { Enhancer of Zeste Homolog } 1 / 2 \\ \text { JMJD3/UTX } & =\text { JmjC-Domain protein } \\ \text { LSD1 } & =\text { Lysine-Specific Demethylase 1 } \\ \text { FBS } & =\text { Fetal Bovine Serum } \\ \text { NCS } & =\text { Newborn Calf Serum } \\ \text { CS } & =\text { Calf Serum } \\ \text { DMEM } & =\text { Dulbecco's Modified Eagle's Medium } \\ \text { SDS } & \text { Sodium Dodecyl Sulfate } \\ \text { DPBS } & =\text { Dulbecco's Phosphate-Buffered Saline } \\ \text { PVDF } & =\text { Polyvinylidene Difluoride } \\ \text { TBST } & =\text { Tris-Buffered Saline with Tween-20 } \\ \text { DES } & =\text { Diethylstilbestrol } \\ \text { E2-BSA } & =\text { Membrane-impermeable Bovine Serum } \\ & \text { Albumin-conjugated 17 } \beta \text {-estradiol } \\ \text { MEK } & =\text { Mitogen-Activated protein Kinase } \\ \text { ERK } & =\text { Extracellular-signal Regulated protein } \\ & \text { Kinases } \\ \text { EAPK } & =\text { Mitogen-Activated Protein Kinase } \\ \text { Elk } & =\text { Transcription factor } \\ & \end{array}$




\section{REFERENCES}

Agger, K., P.A. Cloos, L. Rudkjaer, K. Williams, G. Andersen, J. Christensen and K. Helin, 2009. The $\mathrm{H} 3 \mathrm{~K} 27 \mathrm{me} 3$ demethylase JMJD3 contributes to the activation of the $\mathrm{NK} 4 \mathrm{~A}-\mathrm{ARF}$ locus in response to oncogene- and stress-induced senescence. Genes Dev., 23: 1171-1176.

Bannister, A.J., R. Schneider and T. Kouzarides, 2002. Histone methylation: Dynamic or static? Cell, 109: 801-806.

Barski, A., S. Cuddapah, K. Cui, T.Y. Roh and D.E. Schones, 2007. High-resolution profiling of histone methylations in the human genome. Cell, 129: 823-837.

Bernstein, B.E., T.S. Mikkelsen, X. Xie, M. Kamal and D.J. Huebert et al., 2006. A bivalent chromatin structure marks key developmental genes in embryonic stem cells. Cell, 125: 315-326.

Bodor, C., C. O'Riain, D. Wrench, J. Matthews and S. Iyengar et al., 2011. EZH2 Y641 mutations in follicular lymphoma. Leukemia, 25: 726-729.

Boutin, J.A., 1997. Myristoylation. Cell Signal, 9: 15-35.

Bracken, A.P., D. Pasini, M. Capra, E. Prosperini, E. Colli and $\mathrm{K}$. Helin, 2003. EZH2 is downstream of the pRB$\mathrm{E} 2 \mathrm{~F}$ pathway, essential for proliferation and amplified in cancer. Embo. J., 22: 5323-5335.

Bredfeldt, T.G., K.L. Greathouse, S.H. Safe, M.C. Hung, M.T. Bedford and C.L. Walker, 2010. Xenoestrogeninduced regulation of $\mathrm{EZH} 2$ and histone methylation via estrogen receptor signaling to PI3K/AKT. Mol. Endocrinol., 24: 993-1006.

Cha, T.L., B.P. Zhou, W. Xia, Y. Wu and C.C. Yang et al., 2005. Akt-mediated phosphorylation of $\mathrm{EZH} 2$ suppresses methylation of lysine 27 in histone H3. Science, 310: 306-310.

Czermin, B., R. Melfi, D. McCabe, V. Seitz, A. Imhof and V. Pirrotta, 2002. Drosophila enhancer of Zeste/ESC complexes have a histone $\mathrm{H} 3$ methyltransferase activity that marks chromosomal polycomb sites. Cell, 111: 185-196.

Datta, S.R., H. Dudek, X. Tao, S. Masters, H. Fu, Y. Gotoh and M.E. Greenberg, 1997. Akt phosphorylation of BAD couples survival signals to the cell-intrinsic death machinery. Cell, 91: 231-241.

De Santa, F., M.G. Totaro, E. Prosperini, S. Notarbartolo, G. Testa and G. Natoli, 2007. The histone H3 lysine-27 demethylase Jmjd3 links inflammation to inhibition of polycomb-mediated gene silencing. Cell, 130: 1083-1094.

Esteller, M., 2008. Molecular origins of cancer: Epigenetics in cancer. New England J. Med., 358: 1148-1159.
Ezhkova, E., W.H. Lien, N. Stokes, H.A. Pasolli, J.M. Silva and E. Fuchs, 2011. EZH1 and EZH2 cogovern histone $\mathrm{H} 3 \mathrm{~K} 27$ trimethylation and are essential for hair follicle homeostasis and wound repair. Genes Dev., 25: 485-498.

Feinberg, A.P., R. Ohlsson and S. Henikoff, 2006. The epigenetic progenitor origin of human cancer. Nature Rev. Genet., 7: 21-33.

Fiskus, W., Y. Wang, A. Sreekumar, K.M. Buckley and H. Shi et al., 2009. Combined epigenetic therapy with the histone methyltransferase EZH2 inhibitor 3deazaneplanocin $\mathrm{A}$ and the histone deacetylase inhibitor panobinostat against human AML cells. Blood, 114: 2733-2743.

Fujii, S., K. Tokita, N. Wada, K. Ito, C. Yamauchi, Y. Ito and A. Ochiai, 2011. MEK-ERK pathway regulates $\mathrm{EZH} 2$ overexpression in association with aggressive breast cancer subtypes. Oncogene, 30: 4118-4128.

Ishii, M., H. Wen, C.A. Corsa, T. Liu and A.L. Coelho et al., 2009. Epigenetic regulation of the alternatively activated macrophage phenotype. Blood, 114: 3244-3254.

Jung, J.W., S. Lee, M.S. Seo, S.B. Park, A. Kurtz, S.K. Kang and K.S. Kang, 2010. Histone deacetylase controls adult stem cell aging by balancing the expression of polycomb genes and jumonji domain containing 3. Cell Mol. Life Sci., 67: 1165-1176.

Kleer, C.G., Q. Cao, S. Varambally, R. Shen and I. Ota et al., 2003. EZH2 is a marker of aggressive breast cancer and promotes neoplastic transformation of breast epithelial cells. Proc. Natl. Acad. Sci., 100: 11606-11611.

Kouzarides, T., 2007. Chromatin modifications and their function. Cell, 128: 693-705.

Kuzmichev, A., K. Nishioka, H. Erdjument-Bromage, P. Tempst and D. Reinberg, 2002. Histone methyltransferase activity associated with a human multiprotein complex containing the Enhancer of Zeste protein. Genes Dev., 16: 2893-2905.

Laible, G., A. Wolf, R. Dorn, G. Reuter and C. Nislow et al., 1997. Mammalian homologues of the Polycomb-group gene Enhancer of zeste mediate gene silencing in Drosophila heterochromatin and at S. cerevisiae telomeres. Embo. J., 16: 3219-3232.

Laviola, L., A. Natalicchio and F. Giorgino, 2007. The IGFI signaling pathway. Curr. Pharm. Des., 13: 663-669.

Lee, T.I., R.G. Jenner, L.A. Boyer, M.G. Guenther and S.S. Levine et al., 2006. Control of developmental regulators by Polycomb in human embryonic stem cells. Cell, 125: 301-313.

Livak, K.J. and T.D. Schmittgen, 2001. Analysis of relative gene expression data using Real-time quantitative PCR and the 2 (delta delta $\mathrm{C}(\mathrm{T})$ method. Methods, 25: 402-408. 
Lopez-Carballo, G., L. Moreno, S. Masia, P. Perez and D. Barettino, 2002. Activation of the phosphatidylinositol 3-kinase/Akt signaling pathway by retinoic acid is required for neural differentiation of SH-SY5Y human neuroblastoma cells. J. Biol. Chem., 277: 25297-25304.

Mitsuuchi, Y., S.W. Johnson, S. Moonblatt and J.R. Testa, 1998. Translocation and activation of AKT2 in response to stimulation by insulin. J. Cell Biochem., 70: 433-441.

Mohn, F. and D. Schubeler, 2009. Genetics and epigenetics: Stability and plasticity during cellular differentiation. Trends Genet., 25: 129-136.

Peters, A.H., S. Kubicek, K. Mechtler, R.J. O'Sullivan and A.A. Derijck et al., 2003. Partitioning and plasticity of repressive histone methylation states in mammalian chromatin. Mol. Cell, 12: 1577-1589.

Potter, C.J., L.G. Pedraza and T. Xu, 2002. Akt regulates growth by directly phosphorylating Tsc2. Nat. Cell Biol., 4: 658-665.

Rugg-Gunn, P.J., B.J. Cox, A. Ralston and J. Rossant, 2010. Distinct histone modifications in stem cell lines and tissue lineages from the early mouse embryo. Proc. Natl. Acad. Sci., 107: 10783-10790.

Sasaki, H. and Y. Matsui, 2008. Epigenetic events in mammalian germ-cell development: Reprogramming and beyond. Nat. Rev. Genet., 9: 129-140.

Sato, K., S. Shikano, G. Xia, J. Takao and J.S. Chung et al., 2006. Selective expression of vacuolar $\mathrm{H}+$-ATPase subunit $\mathrm{d} 2$ by particular subsets of dendritic cells among leukocytes. Mol. Immunol., 43: 1443-1453.

Seenundun, S., S. Rampalli, Q.C. Liu, A. Aziz and C. Palii et al., 2010. UTX mediates demethylation of $\mathrm{H} 3 \mathrm{~K} 27 \mathrm{me} 3$ at muscle-specific genes during myogenesis. Embo J., 29: 1401-1411.

Sen, G.L., D.E. Webster, D.I. Barragan, H.Y. Chang and P.A. Khavari, 2008. Control of differentiation in a self-renewing mammalian tissue by the histone demethylase JMJD3. Genes Dev., 22: 1865-1870.

Shaw, T. and P. Martin, 2009. Epigenetic reprogramming during wound healing: Loss of polycomb-mediated silencing may enable upregulation of repair genes. EMBO Rep., 10: 881-886.
Shechter, D., H.L. Dormann, C.D. Allis and S.B. Hake, 2007. Extraction, purification and analysis of histones. Nat. Protocols, 2: 1445-1457.

Shi, Y., F. Lan, C. Matson, P. Mulligan and J. R. Whetstine et al., 2004. Histone demethylation mediated by the nuclear amine oxidase homolog LSD1. Cell, 119: 941-953.

Steward, M.M., J.S. Lee, A. O'Donovan, M. Wyatt, B.E. Bernstein and A. Shilatifard, 2006. Molecular regulation of $\mathrm{H} 3 \mathrm{~K} 4$ trimethylation by $\mathrm{ASH} 2 \mathrm{~L}$, a shared subunit of MLL complexes. Nat. Struct. Mol. Biol., 13: 852-854.

Surani, M.A., K. Hayashi and P. Hajkova, 2007. Genetic and epigenetic regulators of pluripotency. Cell, 128: 747-762.

Tsukada, Y.I., J. Fang, H. Erdjument-Bromage, M.E. Warren, C.H. Borchers, P. Tempst and Y. Zhang, 2006. Histone demethylation by a family of $\mathrm{JmjC}$ domain-containing proteins. Nature, 439: 811-816.

Van Haaften, G., G.L. Dalgliesh, H. Davies, L. Chen and G. Bignell et al., 2009. Somatic mutations of the histone H3K27 demethylase gene UTX in human cancer. Nat. Genet., 41: 521-523.

Van Kemenade, F.J., F.M. Raaphorst, T. Blokzij, E. Fieret and K.M. Hamer et al., 2001. Coexpression of BMI-1 and $\mathrm{EZH} 2$ polycomb-group proteins is associated with cycling cells and degree of malignancy in B-cell non-Hodgkin lymphoma. Blood, 97: 3896-3901.

Varambally, S., Q. Cao, R.S. Mani, S. Shankar and $\mathrm{X}$. Wang et al., 2008. Genomic loss of microRNA-101 leads to overexpression of histone methyltransferase EZH2 in cancer. Science, 322: 1695-1699.

Varambally, S., S.M. Dhanasekaran, M. Zhou, T.R. Barrette and C. Kumar-Sinha et al., 2002. The polycomb group protein $\mathrm{EZH} 2$ is involved in progression of prostate cancer. Nature, 419: 624-629.

Wong, C.F. and R.L. Tellam, 2008. MicroRNA-26a targets the histone methyltransferase Enhancer of Zeste homolog 2 during myogenesis. J. Biol. Chem., 283: 9836-9843.

Xu, J., X. Deng, R. Watkins and C.M. Disteche, 2008. Sex-specific differences in expression of histone demethylases Utx and Uty in mouse brain and neurons. J. Neurosci., 28: 4521-4527. 